\title{
Article \\ The Effect of Non-Thermal Plasma on the Structural and Functional Characteristics of Human Spermatozoa
}

\author{
Eva Tvrdá ${ }^{1}$, Daniel Lovíšek ${ }^{2}$, Stanislav Kyzek $^{2}$, Dušan Kováčik $^{3}$ and Eliška Gálová ${ }^{2, *}$ \\ 1 Department of Animal Physiology, Faculty of Biotechnology and Food Sciences, Slovak University \\ of Agriculture, Tr. A. Hlinku 2, 94976 Nitra, Slovakia; evina.tvrda@gmail.com \\ 2 Department of Genetics, Faculty of Natural Sciences, Comenius University, Ilkovičova 6, Mlynská dolina, \\ 84215 Bratislava, Slovakia; lovisek.daniel@gmail.com (D.L.); kyzek2@uniba.sk (S.K.) \\ 3 Department of Experimental Physics, Faculty of Mathematics, Physics and Informatics, Comenius University, \\ Mlynská dolina, 84248 Bratislava, Slovakia; kovacik@fmph.uniba.sk \\ * Correspondence: eliska.galova@uniba.sk; Tel.: +421-2-602-96268
}

Citation: Tvrdá, E.; Lovíšek, D.; Kyzek, S.; Kováčik, D.; Gálová, E. The Effect of Non-Thermal Plasma on the Structural and Functional Characteristics of Human Spermatozoa. Int. J. Mol. Sci. 2021, 22, 4979. https://doi.org/10.3390/ ijms22094979

Academic Editor: Haim Breitbart

Received: 8 April 2021

Accepted: 3 May 2021

Published: 7 May 2021

Publisher's Note: MDPI stays neutral with regard to jurisdictional claims in published maps and institutional affiliations.

Copyright: (c) 2021 by the authors. Licensee MDPI, Basel, Switzerland. This article is an open access article distributed under the terms and conditions of the Creative Commons Attribution (CC BY) license (https:// creativecommons.org/licenses/by/ $4.0 /$ )

\begin{abstract}
Significant antibacterial properties of non-thermal plasma (NTP) have converted this technology into a promising alternative to the widespread use of antibiotics in assisted reproduction. As substantial data available on the specific in vitro effects of NTP on male reproductive cells are currently missing, this study was designed to investigate selected quality parameters of human spermatozoa ( $n=51)$ exposed to diffuse coplanar surface barrier discharge NTP for $0 \mathrm{~s}, 15 \mathrm{~s}, 30 \mathrm{~s}, 60 \mathrm{~s}$ and $90 \mathrm{~s}$. Sperm motility characteristics, membrane integrity, mitochondrial activity, production of reactive oxygen species (ROS), DNA fragmentation and lipid peroxidation (LPO) were investigated immediately following exposure to NTP and $2 \mathrm{~h}$ post-NTP treatment. Exposure to NTP with a power input of $40 \mathrm{~W}$ for $15 \mathrm{~s}$ or $30 \mathrm{~s}$ was found to have no negative effects on the sperm structure or function. However, a prolonged NTP treatment impaired all the sperm quality markers in a time- and dose-dependent manner. The most likely mechanism of action of high NTP doses may be connected to ROS overproduction, leading to plasma membrane destabilization, LPO, mitochondrial failure and a subsequent loss of motility as well as DNA integrity. As such, our findings indicate that appropriate plasma exposure conditions need to be carefully selected in order to preserve the sperm vitality, should NTP be used in the practical management of bacteriospermia in the future.
\end{abstract}

Keywords: non-thermal plasma; spermatozoa; reactive oxygen species; structural integrity; functional activity

\section{Introduction}

Due to a variety of environmental, occupational and lifestyle factors, the number of couples that benefit from assisted reproduction (AR) is increasing. High-quality spermatozoa and oocytes equally contribute to the success of AR, which is why it is essential to collect and process structurally and functionally competent gametes which will subsequently impact the embryonic development and viability [1,2]. In particular, there is a need to constantly improve protocols for semen processing in order to prevent unnecessary sperm damage before cryopreservation, artificial insemination or in vitro fertilization.

As pointed out by a variety of studies, bacterial contamination of ejaculates has become an essential contributor to excessive sperm degradation in AR clinics. Bacterial adherence to the surface of male gametes followed by sperm agglutination [3,4], motility loss [3,5,6] and an impaired acrosome reaction $[5,6]$ have been observed in bacteria-infested sperm cultures. Furthermore, it has been reported that the use of contaminated sperm suspensions may lead to oocyte degeneration and transmission of infections to the recipients [7].

The advantages of supplementing antibiotics to semen extenders as well as preparation, cryopreservation and IVF media have been questioned for a couple of years now. Despite the ability of antibiotics to prevent bacteriospermia, an increased number of reports 
have emerged emphasizing on the potentially toxic effects of traditional antibiotics on the sperm and embryo vitality [8-10]. These findings, coupled with a dramatically increasing bacterial resistance to antibiotics, have contributed to the need for finding appropriate alternatives to reduce their widespread use during semen handling.

The circumstances mentioned above have led us to the idea that non-thermal plasma (NTP), with the ability to achieve enhanced gas-phase chemistry and high efficiency of microbial inactivation without increasing the gas temperature, could theoretically be used as a replacement to antibiotics for the treatment of semen. The antimicrobial effects of NTP are among the best investigated [11]. Advancements in the design of NTP systems have also underlined their potential for several applications in medicine and biology, such as wound healing, promotion of cell proliferation, tissue regeneration and cancer treatment [12-14]. Furthermore, preliminary studies suggest that NTP could be used to stimulate the motility of spermatozoa collected from asthenozoospermic patients $[15,16]$ and avian species $[17,18]$.

The use of diffuse coplanar surface barrier discharge (DCSBD) is also a perspective NTP technology, which has been successfully applied for the management of bacterial decontamination of biological materials [19]. The portable NTP generator used in our experiments-RPS40 - is based on DCSBD technology. The plasma generated by the RPS40 source exhibits its antibacterial effects most likely due to the production of reactive oxygen species (ROS). However, an equally important aspect of its practical application in biological research lies in the understanding of its impact on human cells which may be in close contact with NTP during treatment. Moreover, spermatozoa appear to be a suitable model for monitoring the NTP effects due to their specifically condensed DNA as well as a lack of repair mechanisms and antioxidant protection. These unique physiological characteristics play a role in an increased sperm susceptibility to oxidative stress, whose mechanisms of action on the male gamete are still not fully understood [20].

As such, this study aimed to determine the potential impact of DCSBD-type NTP on human spermatozoa in vitro.

\section{Results}

The effects of NTP on the proportion of motile spermatozoa are detailed in Tables 1 and 2. Immediately following treatment, significantly lower motility (MOT) and progressive motility (PROG) were detected in the experimental groups subjected to a $60 \mathrm{~s}$ $(p<0.05$ in the case of MOT; $p<0.01$ concerning PROG) and a $90 \mathrm{~s}(p<0.01$ for MOT; $p<0.001$ concerning PROG) exposure to NTP. Possible detrimental effects of an extended NTP treatment on the motion characteristics were recorded after $2 \mathrm{~h}$ post-exposure. A significantly decreased MOT $(p<0.05)$ as well as PROG $(p<0.001)$ were detected in the experimental group exposed to $60 \mathrm{~s}$ of NTP in comparison with the control. Furthermore, an abrupt decline in the motility characteristics was recorded in the group previously subjected to $90 \mathrm{~s}$ of NTP when compared to the control group $(p<0.001)$. No significant changes to MOT or PROG were detected in the samples exposed to $15 \mathrm{~s}$ or $30 \mathrm{~s}$ of NTP (Tables 1 and 2).

Table 1. Motility (MOT) of human spermatozoa $(n=51)$ exposed to NTP of varying time intervals.

\begin{tabular}{cccccc}
\hline MOT [\%] & $\mathbf{0 ~ s}$ & $\mathbf{1 5} \mathbf{s}$ & $\mathbf{3 0 ~ s}$ & $\mathbf{6 0 ~ s}$ & $\mathbf{9 0 ~ s}$ \\
\hline $0 \mathrm{~h}$ & $72.08 \pm 1.69$ & $71.79 \pm 2.23$ & $71.11 \pm 2.55$ & $62.22 \pm 1.99 *$ & $49.22 \pm 1.97^{* *}$ \\
$2 \mathrm{~h}$ & $65.77 \pm 2.63$ & $63.99 \pm 3.12$ & $63.15 \pm 3.51$ & $50.81 \pm 3.13^{*}$ & $37.03 \pm 4.05^{* * *}$ \\
\hline Mean \pm SEM. ${ }^{*} p<0.05 ;{ }^{* *} p<0.01 ;^{* * *} p<0.001$. Lines: times of NTP exposition. Columns: evaluation times.
\end{tabular}

Negative effect of NTP doses of $60 \mathrm{~s}$ and $90 \mathrm{~s}$ on the secondary motility parameters serving as predictors for the overall fertility and chances of pregnancy, represented by the path velocity (VAP) and curvilinear velocity (VCL) revealed itself shortly following treatment in the form of a significant decline of both markers $(p<0.001)$ in comparison 
with the control group. Lower exposure times to NTP (15 s and $30 \mathrm{~s}$ ) had no significant effects neither on VAP (Table 3) nor on VCL (Table 4).

Table 2. Progressive motility (PROG) of human spermatozoa $(n=51)$ exposed to NTP of varying time intervals.

\begin{tabular}{cccccc}
\hline PROG [\%] & $\mathbf{0 ~ s}$ & $\mathbf{1 5 ~ s}$ & $\mathbf{3 0 ~ s}$ & $\mathbf{6 0 ~ s}$ & $\mathbf{9 0 ~ s}$ \\
\hline $0 \mathrm{~h}$ & $40.33 \pm 2.20$ & $40.38 \pm 2.47$ & $35.83 \pm 2.65$ & $24.88 \pm 2.87^{* *}$ & $16.79 \pm 2.74^{* * *}$ \\
$2 \mathrm{~h}$ & $34.08 \pm 3.02$ & $30.38 \pm 2.71$ & $27.00 \pm 2.39$ & $20.25 \pm 3.16^{* * *}$ & $13.42 \pm 3.15^{* * *}$ \\
\hline Mean \pm SEM. ${ }^{* *} p<0.01{ }^{* * *} p<0.001$. & Lines: times of NTP exposition. Columns: evaluation times.
\end{tabular}

Table 3. Path velocity (VAP) of human spermatozoa $(n=51)$ exposed to NTP of varying time intervals.

\begin{tabular}{cccccc}
\hline VAP $[\mu \mathrm{m} / \mathrm{s}]$ & $\mathbf{0 ~ s}$ & $\mathbf{1 5}$ & $\mathbf{3 0 ~}$ & $\mathbf{6 0 ~ s}$ & $\mathbf{9 0 ~ s}$ \\
\hline $0 \mathrm{~h}$ & $54.32 \pm 2.41$ & $52.56 \pm 0.20$ & $51.56 \pm 1.73$ & $39.70 \pm 1.68^{* * *}$ & $34.89 \pm 1.98^{* * *}$ \\
$2 \mathrm{~h}$ & $46.26 \pm 3.83$ & $42.74 \pm 1.92$ & $40.32 \pm 2.35$ & $36.13 \pm 1.89^{* * *}$ & $30.79 \pm 3.57^{* * *}$ \\
\hline
\end{tabular}

Mean \pm SEM. ${ }^{* * *} p<0.001$. Lines: times of NTP exposition. Columns: evaluation times.

Table 4. Curvilinear velocity (VCL) of human spermatozoa $(n=51)$ exposed to NTP of varying time intervals.

\begin{tabular}{cccccc}
\hline VCL $[\mu \mathrm{m} / \mathrm{s}]$ & $\mathbf{0 ~ s}$ & $\mathbf{1 5} \mathbf{s}$ & $\mathbf{3 0}$ & $\mathbf{6 0 ~ s}$ & $\mathbf{9 0 ~ s}$ \\
\hline $0 \mathrm{~h}$ & $85.53 \pm 3.06$ & $80.28 \pm 2.35$ & $80.20 \pm 2.24$ & $62.98 \pm 1.63^{* * * *}$ & $57.83 \pm 2.22^{* * * *}$ \\
$2 \mathrm{~h}$ & $72.76 \pm 4.71$ & $68.99 \pm 2.51$ & $67.47 \pm 2.35$ & $50.90 \pm 1.69^{* * * *}$ & $50.73 \pm 4.11^{* * * *}$ \\
\hline
\end{tabular}

Mean \pm SEM. ${ }^{* * * *} p<0.0001$. Lines: times of NTP exposition. Columns: evaluation times.

Assessment of both characteristics $2 \mathrm{~h}$ post-NTP treatment showed further decline of VAP as well as VCL which remained significant in the samples subjected to $60 \mathrm{~s}$ as well as $90 \mathrm{~s}(p<0.001)$ of NTP when compared with the control.

The analysis of motion characteristics necessary for cervical mucus penetration, including the straight line velocity (VSL), straightness (STR) and lateral amplitude (ALH) reveal that amongst the observed parameters, VSL was the most affected by high NTP exposition times. A significant decrease of VSL was observed immediately $(0 \mathrm{~h})$ following exposure do $60 \mathrm{~s}$ and $90 \mathrm{~s}$ of NTP $(p<0.001)$ in comparison to the control group. A similar observation was recorded $2 \mathrm{~h}$ following NTP treatment (Table 5).

Table 5. Straight line velocity (VSL) of human spermatozoa $(n=51)$ exposed to NTP of varying time intervals.

\begin{tabular}{cccccc}
\hline VSL $[\boldsymbol{\mu m} / \mathbf{s}]$ & $\mathbf{0 ~ s}$ & $\mathbf{1 5 ~} \mathbf{~}$ & $\mathbf{3 0 ~}$ & $\mathbf{6 0 ~ s}$ & $\mathbf{9 0 ~ s}$ \\
\hline $0 \mathrm{~h}$ & $46.89 \pm 2.53$ & $44.16 \pm 2.26$ & $42.81 \pm 1.89$ & $32.29 \pm 2.18^{* * *}$ & $27.26 \pm 2.53^{* * * *}$ \\
$2 \mathrm{~h}$ & $38.78 \pm 4.13$ & $32.71 \pm 2.25$ & $31.62 \pm 2.69$ & $25.52 \pm 2.31^{* * *}$ & $20.28 \pm 4.04^{* * * *}$ \\
\hline
\end{tabular}

In the meantime, immediate NTP treatment had no significant impact on STR (Table 6) or ALH (Table 7); nevertheless, at $2 \mathrm{~h}$, a significant decline of both parameters was observed in the experimental groups previously subjected to $60 \mathrm{~s}(p<0.05)$ as well as $90 \mathrm{~s}$ of NTP when compared to the control group.

Table 6. Straightness (STR) of human spermatozoa $(n=51)$ exposed to NTP of varying time intervals.

\begin{tabular}{cccccc}
\hline STR [\%] & 0 s & 15 s & 30 s & 60 s & 90 s \\
\hline $0 \mathrm{~h}$ & $83.00 \pm 1.94$ & $82.44 \pm 1.52$ & $81.56 \pm 1.59$ & $79.00 \pm 2.25$ & $75.89 \pm 3.01$ * \\
$2 \mathrm{~h}$ & $80.44 \pm 2.68$ & $78.58 \pm 1.89$ & $77.51 \pm 2.05$ & $76.32 \pm 3.08$ & $64.56 \pm 6.83$ * \\
\hline
\end{tabular}

Mean \pm SEM. ${ }^{*} p<0.05$. Lines: times of NTP exposition. Columns: evaluation times. 
Table 7. Lateral amplitude (ALH) of human spermatozoa $(n=51)$ exposed to NTP of varying time intervals.

\begin{tabular}{cccccc}
\hline ALH $[\boldsymbol{\mu m}]$ & $\mathbf{0 ~ s}$ & $\mathbf{1 5} \mathbf{~ s}$ & $\mathbf{3 0 ~ s}$ & $\mathbf{6 0 ~ s}$ & $\mathbf{9 0 ~ s}$ \\
\hline $0 \mathrm{~h}$ & $3.85 \pm 0.18$ & $3.85 \pm 0.19$ & $3.44 \pm 0.29$ & $3.44 \pm 0.023$ & $2.84 \pm 0.24^{*}$ \\
$2 \mathrm{~h}$ & $3.57 \pm 0.20$ & $3.43 \pm 0.14$ & $3.43 \pm 0.13$ & $2.91 \pm 0.41$ & $2.76 \pm 0.41^{*}$ \\
\hline Mean \pm SEM. ${ }^{*} p<0.05$. Lines: times of NTP exposition. Columns: evaluation times.
\end{tabular}

Finally, assessment of the beat cross frequency (BCF) and linearity (LIN) as parameters estimating the ability of spermatozoa to move throughout the uterus and Fallopian tubes indicates that among these, BCF was more affected by the NTP treatment than LIN. A significant decrease of BCF was recorded in the experimental groups subjected to NTP for $60 \mathrm{~s}$ as well as $90 \mathrm{~s}(p<0.05$; Table 8$)$ when compared to the control group immediately following NTP treatment as well as $2 \mathrm{~h}$ post-exposure.

Table 8. Beat cross frequency $(\mathrm{BCF})$ of human spermatozoa $(n=51)$ exposed to NTP of varying time intervals.

\begin{tabular}{cccccc}
\hline BCF [Hz] & $\mathbf{0 ~ s}$ & $\mathbf{1 5 ~}$ & $\mathbf{3 0 ~ s}$ & $\mathbf{6 0 ~ s}$ & $\mathbf{9 0 ~ s}$ \\
\hline $0 \mathrm{~h}$ & $28.39 \pm 1.09$ & $26.81 \pm 0.97$ & $26.56 \pm 1.22$ & $24.53 \pm 1.16^{*}$ & $24.03 \pm 0.82 *$ \\
$2 \mathrm{~h}$ & $25.50 \pm 1.12$ & $24.10 \pm 2.31$ & $23.93 \pm 2.27$ & $21.91 \pm 1.22 *$ & $21.13 \pm 3.11^{*}$ \\
\hline
\end{tabular}

In case of LIN, at $0 \mathrm{~h}$ (Table 9), a decrease of the parameter was observed, particularly in case of NTP doses of $60 \mathrm{~s}$ and $90 \mathrm{~s}$, although all changes were insignificant. A similar observation was recorded $2 \mathrm{~h}$ following NTP treatment. A decline of LIN was recorded in case of the experimental groups exposed to $60 \mathrm{~s}$ of NTP and this trend became more profound following the longest plasma exposure time (90 s). Nevertheless, no significant changes were detected.

Table 9. Linearity (LIN) of human spermatozoa $(n=51)$ exposed to NTP of varying time intervals.

\begin{tabular}{cccccc}
\hline LIN [\%] & $\mathbf{0 ~ s}$ & $\mathbf{1 5}$ & $\mathbf{3 0 ~}$ & $\mathbf{6 0 ~ s}$ & $\mathbf{9 0 ~ s}$ \\
\hline $0 \mathrm{~h}$ & $55.11 \pm 2.29$ & $54.89 \pm 2.48$ & $54.00 \pm 2.81$ & $51.00 \pm 2.50$ & $47.22 \pm 3.32$ \\
$2 \mathrm{~h}$ & $52.56 \pm 3.28$ & $50.44 \pm 2.11$ & $49.78 \pm 2.33$ & $49.11 \pm 2.93$ & $45.44 \pm 2.62$ \\
\hline
\end{tabular}

Mean \pm SEM. Lines: times of NTP exposition. Columns: evaluation times.

Qualitative changes in the sperm membranes related to the process of apoptosis or necrosis were determined using the Annexin $\mathrm{V}(\mathrm{AV})$ and propidium iodide (PI) fluorescent staining protocol $0 \mathrm{~h}$ and $2 \mathrm{~h}$ after $0 \mathrm{~s}, 15 \mathrm{~s}, 30 \mathrm{~s}, 60 \mathrm{~s}$ and $90 \mathrm{~s}$ of NTP treatment. It may be observed that immediately following exposure to NTP, the proportion of apoptotic (Table 10) and necrotic spermatozoa (Table 11) increased in a dose-dependent manner when compared to the control. The most significant apoptotic or necrotic disruption of the sperm membranes at $0 \mathrm{~h}$ was observed in case of the experimental group subjected to a $90 \mathrm{~s}$ NTP treatment $(p<0.05$ in case of AV-positivity; $p<0.01$ with respect of PI-positivity).

Table 10. Apoptotic changes to the membrane of human spermatozoa $(n=51)$ exposed to NTP of varying time intervals.

\begin{tabular}{cccccc}
\hline AV-Positivity [\%] & $\mathbf{0 ~ s}$ & $\mathbf{1 5}$ & $\mathbf{3 0 ~}$ & $\mathbf{6 0 ~ s}$ & $\mathbf{9 0 ~ s}$ \\
\hline $0 \mathrm{~h}$ & $10.97 \pm 0.99$ & $11.07 \pm 2.00$ & $12.47 \pm 1.99$ & $15.77 \pm 2.88$ & $17.66 \pm 2.57^{*}$ \\
$2 \mathrm{~h}$ & $13.27 \pm 2.08$ & $14.02 \pm 1.45$ & $17.08 \pm 2.12$ & $22.89 \pm 3.05^{*}$ & $28.30 \pm 2.75^{* * *}$ \\
\hline
\end{tabular}

AV-Annexin V. Mean \pm SEM. ${ }^{*} p<0.05 ;^{* * *} p<0.001$. Lines: times of NTP exposition. Columns: evaluation times. 
Table 11. Necrotic changes to the membrane of human spermatozoa $(n=51)$ exposed to NTP of varying time intervals.

\begin{tabular}{cccccc}
\hline PI-Positivity [\%] & $\mathbf{0 ~ s}$ & $\mathbf{1 5} \mathbf{~ s}$ & $\mathbf{3 0 ~}$ & $\mathbf{6 0 ~ s}$ & $\mathbf{9 0 ~ s}$ \\
\hline $0 \mathrm{~h}$ & $5.55 \pm 0.99$ & $6.12 \pm 1.34$ & $6.76 \pm 1.96$ & $10.15 \pm 1.92 *$ & $12.06 \pm 1.99 * *$ \\
$2 \mathrm{~h}$ & $7.99 \pm 1.97$ & $8.32 \pm 2.05$ & $9.07 \pm 2.19$ & $15.55 \pm 2.14 *$ & $19.22 \pm 2.55^{* *}$ \\
\hline
\end{tabular}

PI-Propidium iodide. Mean \pm SEM. ${ }^{*} p<0.05$; ${ }^{* *} p<0.01$. Lines: times of NTP exposition. Columns: evaluation times.

An interesting observation was noted in the case of the changing ratio of early apoptotic cells to necrotic cells. In the unaffected sample as well as following NTP treatment of $15 \mathrm{~s}$ and $30 \mathrm{~s}$, a slight predominance of cells in early apoptosis was noted (Table 10). However, this trend reversed in favour of necrotic (or late apoptotic) cells at a $60 \mathrm{~s}$ dose and was even more pronounced at $90 \mathrm{~s}$ (Table 11).

The analysis at $2 \mathrm{~h}$ following NTP treatment revealed more radical membrane damage in comparison to the assessment immediately following exposure to NTP. A significantly higher percentage of cells exhibiting signs of early apoptosis (Table 10) as well as late apoptosis or necrosis (Table 11) was detected in the groups previously exposed to $60 \mathrm{~s}$ $(p<0.05)$ and $90 \mathrm{~s}(p<0.001$ for AV-positivity; $p<0.01$ in case of PI-positivity).

At $0 \mathrm{~h}$ (Table 12), a slight increase in the mitochondrial activity of the experimental group subjected to the lowest NTP exposure time (15 s) was observed. By increasing the plasma exposure time to $30 \mathrm{~s}$ and $60 \mathrm{~s}$, the mitochondrial function recorded was almost equal to the control values. At the maximum exposure time (90 s), the sperm mitochondrial activity slightly decreased when compared to the control. All changes in the sperm metabolic function were insignificant.

Table 12. Mitochondrial activity of human spermatozoa $(n=51)$ exposed to NTP of varying time intervals.

\begin{tabular}{cccccc}
\hline MTT Test [\%] & $\mathbf{0 ~ s}$ & $\mathbf{1 5 ~ s}$ & $\mathbf{3 0 ~ s}$ & $\mathbf{6 0 ~ s}$ & $\mathbf{9 0 ~ s}$ \\
\hline $0 \mathrm{~h}$ & $100.00 \pm 0.00$ & $109.01 \pm 7.11$ & $103.00 \pm 8.33$ & $102.20 \pm 6.78$ & $94.44 \pm 7.79$ \\
$2 \mathrm{~h}$ & $100.00 \pm 0.00$ & $110.20 \pm 8.87$ & $104.42 \pm 7.53$ & $90.66 \pm 9.17$ & $88.62 \pm 9.49$ \\
\hline
\end{tabular}

A similar observation was recorded $2 \mathrm{~h}$ following NTP treatment (Table 12). A decrease of the mitochondrial metabolism was noted in case of the experimental group exposed to $60 \mathrm{~s}$ of NTP and this decline became even more pronounced following the highest plasma exposure time (90 s). Nevertheless, no significant changes were recorded.

Inversely, the JC-1 assay revealed the first differences in the mitochondrial membrane potential $(\Delta \psi \mathrm{m})$ immediately following a $90 \mathrm{~s}$ exposure to NTP, reflected in a significantly lower mitochondrial vitality $(p<0.05)$ when compared to the control (Table 13). Disrupting effects of NTP on $\Delta \psi \mathrm{m}$ were observed following $2 \mathrm{~h}$ as well. At the end of the experiment, the lowest $\Delta \psi \mathrm{m}$ was detected in the experimental groups subjected to a $60 \mathrm{~s}(p<0.05)$ and a 90 s exposure $(p<0.01)$ to NTP (Table 13).

Table 13. The mitochondrial membrane potential of human spermatozoa $(n=51)$ exposed to NTP of varying time intervals.

\begin{tabular}{cccccc}
\hline $\boldsymbol{\Delta} \mathbf{w} \mathbf{m}[\mathbf{R e d} / G r e e n$ Ratio] & $\mathbf{0 ~ s}$ & $\mathbf{1 5}$ & $\mathbf{3 0 ~ s}$ & $\mathbf{6 0 ~ s}$ & $\mathbf{9 0 ~ s}$ \\
\hline $0 \mathrm{~h}$ & $3.26 \pm 0.30$ & $3.23 \pm 0.31$ & $3.20 \pm 0.34$ & $3.00 \pm 0.28$ & $2.74 \pm 0.19^{*}$ \\
$2 \mathrm{~h}$ & $2.39 \pm 0.21$ & $2.33 \pm 0.17$ & $2.22 \pm 0.23$ & $1.56 \pm 0.17^{*}$ & $1.25 \pm 0.09^{* *}$ \\
\hline
\end{tabular}

Mean \pm SEM. ${ }^{*} p<0.05 ;{ }^{* *} p<0.01$. Lines: times of NTP exposition. Columns: evaluation times.

The effect of NTP on the sperm nuclear DNA manifested itself immediately following treatment in the form of an increased rate of DNA fragmentation. Lower exposure times to NTP (15 s and $30 \mathrm{~s}$ ) had no significant effects on the rate of DNA damage, while a significant increase of cells exhibiting a fragmented DNA molecule was observed at doses 
of $60 \mathrm{~s}$ and $90 \mathrm{~s}(p<0.001)$ when compared to the control. Interestingly, by increasing the NTP dose from $60 \mathrm{~s}$ to $90 \mathrm{~s}$, the DNA fragmentation index did not increase further (Table 14).

Table 14. DNA fragmentation of human spermatozoa $(n=51)$ exposed to NTP of varying time intervals.

\begin{tabular}{cccccc}
\hline DNA Fragmentation Index [\%] & $\mathbf{0 ~ s}$ & $\mathbf{1 5} \mathbf{s}$ & $\mathbf{3 0 ~ s}$ & $\mathbf{6 0 ~ s}$ & $\mathbf{9 0 ~ s}$ \\
\hline $0 \mathrm{~h}$ & $12.84 \pm 2.60$ & $13.94 \pm 1.91$ & $14.77 \pm 1.92$ & $26.55 \pm 3.26^{* * *}$ & $27.62 \pm 3.53^{* * *}$ \\
$2 \mathrm{~h}$ & $18.98 \pm 3.10$ & $20.02 \pm 2.10$ & $22.21 \pm 2.41$ & $39.60 \pm 3.12^{* * *}$ & $48.92 \pm 3.90^{* * *}$ \\
\hline
\end{tabular}

Mean \pm SEM. ${ }^{* * *} p<0.01$. Lines: times of NTP exposition. Columns: evaluation times.

Assessment of the DNA fragmentation index after $2 \mathrm{~h}$ post-NTP treatment led to slightly different results in comparison to $0 \mathrm{~h}$. Substantial changes occurred at a dose of $60 \mathrm{~s}$ and $90 \mathrm{~s}$ caused significant DNA damage to the male gametes, which was as twice as high in comparison to the unaffected control $(p<0.001)$. Notable dose-dependent differences in the progress of sperm DNA damage were also recorded concerning NTP exposure times of $60 \mathrm{~s}$ and $90 \mathrm{~s}$, which were not observed at $0 \mathrm{~h}$.

At $0 \mathrm{~h}, \mathrm{ROS}$ production in the experimental groups increased proportionally depending on the increasing dose of NTP (Table 15). A slightly increased ROS concentration was observed following a $15 \mathrm{~s}$ and $30 \mathrm{~s}$ exposure to NTP when compared to the untreated sample. Nevertheless, a significant rise in the ROS production was recorded in the experimental groups subjected to NTP for $60 \mathrm{~s}(p<0.05)$ and $90 \mathrm{~s}(p<0.01)$ in comparison to the control group. ROS-promoting effects of NTP were observed following $2 \mathrm{~h}$ post-treatment, as significantly higher ROS amounts were found in the experimental groups subjected to NTP for $60 \mathrm{~s}(p<0.05)$ as well as $90 \mathrm{~s}(p<0.01)$ against the control.

Table 15. Reactive oxygen species (ROS) production by human spermatozoa $(n=51)$ exposed to NTP of varying time intervals.

\begin{tabular}{cccccc}
\hline ROS [RLU/s/106 $\mathbf{s p e r m}]$ & $\mathbf{0 ~ s}$ & $\mathbf{1 5}$ & $\mathbf{3 0 ~ s}$ & $\mathbf{6 0 ~ s}$ & $\mathbf{9 0 ~ s}$ \\
\hline $0 \mathrm{~h}$ & $25.54 \pm 3.18$ & $27.93 \pm 3.55$ & $29.34 \pm 4.00$ & $37.33 \pm 3.87 *$ & $45.28 \pm 4.62 * *$ \\
$2 \mathrm{~h}$ & $29.99 \pm 4.07$ & $32.33 \pm 4.22$ & $34.41 \pm 3.57$ & $42.44 \pm 4.71 *$ & $51.88 \pm 4.86 * *$ \\
\hline
\end{tabular}

Mean \pm SEM. ${ }^{*} p<0.05 ;{ }^{* *} p<0.01$. Lines: times of NTP exposition. Columns: evaluation times.

Immediately following treatment $(0 \mathrm{~h})$, a slightly increased superoxide concentration was observed in all experimental group subjected to NTP (Table 16).

Table 16. Superoxide production by human spermatozoa $(n=51)$ exposed to NTP of varying time intervals.

\begin{tabular}{cccccc}
\hline NBT Test [\%] & $\mathbf{0 ~ s}$ & $\mathbf{1 5}$ & $\mathbf{3 0} \mathbf{s}$ & $\mathbf{6 0 ~ s}$ & $\mathbf{9 0 ~ s}$ \\
\hline $0 \mathrm{~h}$ & $100.00 \pm 0.00$ & $102.44 \pm 7.79$ & $102.20 \pm 6.78$ & $106.08 \pm 9.76$ & $107.09 \pm 9.03$ \\
$2 \mathrm{~h}$ & $100.00 \pm 0.00$ & $107.88 \pm 7.77$ & $109.22 \pm 8.98$ & $116.96 \pm 9.92$ & $124.03 \pm 9.19$ \\
\hline
\end{tabular}

Mean \pm SEM. Lines: times of NTP exposition. Columns: evaluation times.

At $2 \mathrm{~h}$ following exposure to NTP, an increase of superoxide generation was noted particularly in the case of the experimental group subjected to $60 \mathrm{~s}$ of NTP and this rising tendency became even more distinct following the highest exposure time to NTP (90 s). Nevertheless, no significant differences against the control were recorded.

The thiobarbituric acid reactive substances (TBARS) assay revealed that NTP exhibits the ability to induce ROS-inflicted damage to the sperm lipids (Table 17). A significantly increased malondialdehyde (MDA) concentration was detected immediately $(0 \mathrm{~h})$ following a 90 s exposure to NTP $(p<0.05)$ in comparison with the untreated control. After $2 \mathrm{~h}$, a significantly higher LPO was recorded in the case of samples subjected to a $60 \mathrm{~s}(p<0.05)$ and $90 \mathrm{~s}(p<0.01)$ NTP treatment. No significant changes in the samples exposed to NTP for $15 \mathrm{~s}$ and $30 \mathrm{~s}$ were observed. 
Table 17. Lipid peroxidation of human spermatozoa $(n=51)$ exposed to NTP of varying time intervals.

\begin{tabular}{|c|c|c|c|c|c|}
\hline $\operatorname{MDA}[\mu \mathrm{mol} / \mathrm{L}]$ & $0 \mathrm{~s}$ & $15 s$ & $30 \mathrm{~s}$ & $60 \mathrm{~s}$ & $90 \mathrm{~s}$ \\
\hline $0 \mathrm{~h}$ & $0.62 \pm 0.08$ & $0.63 \pm 0.06$ & $0.67 \pm 0.07$ & $0.77 \pm 0.08$ & $0.88 \pm 0.09 *$ \\
\hline $2 \mathrm{~h}$ & $0.77 \pm 0.09$ & $0.79 \pm 0.07$ & $0.84 \pm 0.09$ & $1.09 \pm 0.12 *$ & $1.32 \pm 0.13^{* *}$ \\
\hline
\end{tabular}

Mean \pm SEM. ${ }^{*} p<0.05 ;{ }^{* *} p<0.01$. Lines: times of NTP exposition. Columns: evaluation times.

\section{Discussion}

When examining the potential application of NTP in biology and medicine, particular attention must be devoted to understanding how specifically NTP affects the cell and which of its components could be responsible for any observed changes in the cell behaviour. Describing this interaction at the molecular level may be complicated due to the intricate nature of NTP and the heterogeneity of biological targets. At the same time, we must take into account that all components of the plasma travel a certain distance and often trespass different environments (e.g., air/water interface) when affecting a given subject, which creates space for various interactions that can lead to the formation of new components [21].

As this study focused primarily on the changes of the structural integrity and functional activity of spermatozoa in response to NTP, we focused on the exclusion of any additional factors that could have a potential impact on the obtained data. Previous studies on the effect of plasma on DNA in aqueous solutions partially helped us to select an appropriate culture medium for the collected semen samples. It has been suggested that complex media could interact with the plasma components (particularly ROS) [22] or change their properties (such as $\mathrm{pH}$ ) in response to NTP treatment [23]. Similarly, data collected from the chemiluminescent assay for ROS quantification should be interpreted with caution due to a variety of factors that may affect the signal obtained, such as the medium composition or its $\mathrm{pH}$ [24]. As such, we chose the simplest possible medium in the form of saline to dilute the ejaculates.

A plasma device that actively generates NTP is characterized by an unmistakable blue-violet light (UV) and a strong odour of ozone. It is well known that these two components are biologically active. However, it is debatable to what extent and whether UV and/or ozone from the plasma could contribute to its overall effect. Lunov et al. [25] compared the impact of NTP and ozone itself on selected bacteria (Pseudomonas aeruginosa and Staphylococcus aureus) as well as mammalian cell lines (3T3 fibroblasts and glioma cells). The authors confirmed the inhibitory effects of NTP as well as ozone on the bacteria. However, it was found that the cytotoxic effect of ozone alone was stronger and faster in comparison to a heterogenic NTP in case of the tested cell lines. The proposed mechanism of ozone toxicity lies in the induction of a rapid accumulation of ROS in the cell, which could lead to cell death, particularly necrosis. In this study, we also observed an immediate inhibitory effect of prolonged exposure to NTP on the selected sperm quality parameters, which could indicate that the plasma generated by the RPS40 device could contain a significant amount of ozone. However, the interpretation of the results in this direction is complicated since the exact composition of the plasma produced at a specific moment is difficult to be determined.

The presence of even relatively low concentrations of ozone may be detected by the sense of smell [26]. Nevertheless, the perception of ozone during the treatment of samples does not necessarily mean that it contributes significantly to the detrimental effects of high NTP doses on male reproductive cells. On the other hand, Gradil et al. [27] demonstrated that even a relatively low dose $(5 \mu \mathrm{g} / \mathrm{mL})$ of ozone exhibited spermicidal effects on bovine specimens. In this sense, we may agree with the authors, that the cause could lie in damage to the cytoplasmic membrane due to oxidative stress, or a decreased availability of ATP or cAMP for the motility process. However, by summarizing the data available so far, we cannot assess the extent to which ozone from the RPS40 plasma generator contributes to our observations. Therefore, we cannot rule out its possible application in andrology.

UV radiation from plasma seems to be relevant mainly because of its inhibitory effects on bacteria [28]. In eukaryotes, however, the contribution of UV to the overall impact 
of NTP is unknown, some authors even claim that it is negligible [12,29]. In order to deny the influence of UV, it is necessary to clarify if and how it affects sperm survival. UV radiation is defined by the wavelengths of the electromagnetic spectrum in the range from 100-400 nm. Most studies looked at the effects of shorter wavelength UV radiation because it interacts easily with DNA and induces ROS overproduction, thus exhibiting large genotoxicity $[30,31]$.

The effect of UV-C radiation ( $254 \mathrm{~nm}$ ) was tested on human spermatozoa. These were resuspended in a nutrient medium and treated at a distance of $4 \mathrm{~cm}$ for $0,10,20$ and $30 \mathrm{~min}$, corresponding to UV-C doses of $0,7.92,15.84$ and $23.76 \mathrm{~kJ} / \mathrm{m}^{2}$. Similarly to our results, high doses of UV-C reduced the sperm motility by damaging membranes through LPO [30]. Other reports compared the effect of UV radiation on spermatozoa obtained from fertile and infertile men and looked at whether they differed in their susceptibility to DNA damage by UV radiation. Using a neutral comet assay, they found that after $15 \mathrm{~min}$ of UV-C irradiation ( $254 \mathrm{~nm}$ ) at a source distance of $1 \mathrm{~m}$, the rate of DNA fragmentation increased slightly more in the specimens of infertile men.

Nevertheless, DNA damage was also reported in samples collected from fertile subjects [31]. Interestingly, UV-A $(365 \mathrm{~nm})$ radiation with lower energy, which is not primarily absorbed by the DNA molecule, also exhibited a damaging effect on male gametes. UV-A treatment of human spermatozoa resulted in a gradual loss of their motility and consequently in a reduction of their overall survival. The explanation could lie in the induction of oxidative stress by this type of radiation [32]. Summarizing the studies mentioned above, a relatively wide spectrum of UV radiation exhibits adverse effects on essential sperm parameters such as motility or DNA and membrane integrity. We recorded similar results, particularly concerning high doses of NTP. Nevertheless, a definitive conclusion cannot be postulated, as specific information on the RPS40 electromagnetic spectrum still needs to be investigated. Furthermore, our specimens were subjected to a complete plasma, without any filters that would separate its individual components and thus allow us to assess their separate effects.

In the context of the biological effects of plasma on living cells, NTP can be considered as an inducer of oxidative stress. Not only is plasma itself a source of ROS, but it induces their further production in response by the cells [33]. A similar property is characteristic of hydrogen peroxide $\left(\mathrm{H}_{2} \mathrm{O}_{2}\right)$, which belongs to the ROS family. Still, in the intracellular environment, it can become a source of other free radicals due to the Fenton and HaberWeiss reactions. Furthermore, it is a molecule with a high affinity to lipids.

The effect of oxidative stress on human spermatozoa induced by $\mathrm{H}_{2} \mathrm{O}_{2}$ has been tested by several authors [34-36]. All studies revealed that exogenously administered $\mathrm{H}_{2} \mathrm{O}_{2}$ reduced the sperm motility as well as mitochondrial activity, increased the total intracellular concentration of ROS and the degree of DNA fragmentation. This intracellular rise in $\mathrm{ROS}$ amounts can be explained by direct diffusion of $\mathrm{H}_{2} \mathrm{O}_{2}$ across the membranes or its incorporation into intracellular pro-oxidative processes. ROS overproduction is considered to be a prime cause of a decreased motility. In addition, high ROS concentrations are associated with peroxidation of membrane lipids and a subsequent loss of the selective permeability and stability of membranous structures. A prooxidant intracellular signalling machinery will be initiated, in which highly reactive LPO end-products may directly damage critical biomacromolecules as well as whole organelles, such as mitochondria [37], which may subsequently become a significant source of ROS themselves, intensifying the risk for irreversible oxidative damage to the cell $[34,36]$. Oxidative stress is also considered to be a major cause for DNA damage in spermatozoa [35].

Looking at the results obtained from our experiments, several trends can be observed, which may provide more clarification to the NTP impact on human spermatozoa. Our first observation is that high NTP doses exhibited a detrimental impact on almost all observed sperm parameters. The only exception was the mitochondrial activity assessed by the MTT test and the intracellular superoxide production. Both seemed to be unaffected by even high NTP exposure times, although a tendency indicating damage to the mitochondrial 
machinery could be observed following $2 \mathrm{~h}$ post-NTP treatment. The dependence of the sperm kinetic system on ATP, which is by and large created by oxidative phosphorylation in mitochondria, has been proven on numerous occasions [38]. In addition, these parameters were correlated in several earlier studies [36,39-41]. On the other hand, an interesting explanation for reduced sperm motility could be provided by a mitochondrial-independent mechanism, which consists in direct oxidative damage to the contractile apparatus of the flagellum (specifically damage to the axoneme or flagellar envelope structures) or in a reduced ability of the sperm cell to actually take advantage of ATP. This hypothesis is based on an earlier study commenting that induced oxidative stress did not cause a change in the activity of the respiratory chain or the amount of intracellular ATP [42]. Similar conclusions are summarized in a report on the effects of oxidative stress generated by the xanthine/xanthine oxidase system on stallion spermatozoa [43]. To provide clarification to these contradictory statements, besides the MTT test, we chose to evaluate the mitochondrial function using the JC-1 assay. In this case, we observed a time- and dose-dependent decrease of the mitochondrial function, which mirrored the decline of the motility characteristics obtained from the CASA analysis. As such, we may speculate that the first cellular components affected by high doses of NTP are the membranous structures of the sperm cell. In addition, the plasma membrane, the outer mitochondrial membrane as a representative of the mitochondrial membrane potential may become a suitable target for the reactive components of NTP. Thus, decreased sperm motility observed immediately following NTP treatment may be a consequence of a disrupted intracellular milieu caused by the membrane destabilization as well as other mitochondria-independent mechanisms as indicated earlier. At later stages, potential alterations to the inner mitochondrial membrane may be expected, leading to a decrease of the activity of the electron transport chain and subsequent ROS leakage from damaged mitochondria, contributing to further sperm immobilization. In addition to the membrane disintegration, peroxidation of membrane lipids takes place due to the high content of polyunsaturated fatty acids in the sperm membranes, which are highly susceptible to oxidative damage [37,44]. Lastly, DNA fragmentation could be attributed to a high vulnerability of the sperm genetic material to oxidative stress. Although the DNA molecule is, in theory, well protected by high levels of nuclear condensation $[35,45]$, by trespassing a critical ROS threshold, subsequent oxidative insults are unavoidable and the resulting damage is impossible to be reversed, as the male gamete lacks a cytoplasm with proper antioxidant or repair mechanisms.

Another observation from this study is that the effects of high plasma doses manifested themselves immediately following treatment on all measured parameters, without the need for preincubation. This suggests that some of the physical components of plasma, which may be characterized by such immediate action, could be responsible for the detected changes in the sperm vitality [30]. While UV, as a critical component of NTP, has not gained significant support from the scientific community as discussed earlier [12,29], this acute toxicity could be indeed caused by ozone, which is a ROS. It could be responsible for increased oxidative pressure on living cells [25]. Accordingly, we detected an increased amount of ROS in the specimens exposed to NTP, which could have been responsible for elevated damage to the sperm DNA and lipids, as suggested by a number of earlier studies [46-48]. Nevertheless, we must still emphasize on the fact that it is difficult to determine which of the physical or chemical components of the plasma could be the key one in evoking such a biological reaction. Hence, we may speculate about a synergistic effect of the individual components [49].

The last important observation from our study is the fact that NTP had a significant negative effect on the selected sperm parameters at higher doses exclusively, specifically at 60 and $90 \mathrm{~s}$ of exposure. No significant positive or negative impact of the plasma was observed in case of a lower exposure time. It is known that the toxic effects of an equal NTP dose are higher in the case of prokaryotic cells when compared to eukaryotic cells [50]. Assuming lower NTP doses used in our experiments are effective enough to exhibit substantial antibacterial effects, the RPS40 plasma generator could become an interesting 
strategy to at least decrease the bacterial contamination of semen samples. Nevertheless, to reach a definitive conclusion, further studies on the effects of NTP generated by the RPS40 instrument on selected uropathogenic bacteria or contaminated semen samples are crucial.

\section{Materials and Methods}

\subsection{RPS40 Plasma Generator Characteristics}

Non-thermal plasma was generated by the diffuse coplanar surface barrier discharge installed in a small handheld; portable ambient air plasma system made by Roplass s.r.o. (Brno, Czech Republic) under the designation RPS40 (Figure 1a).

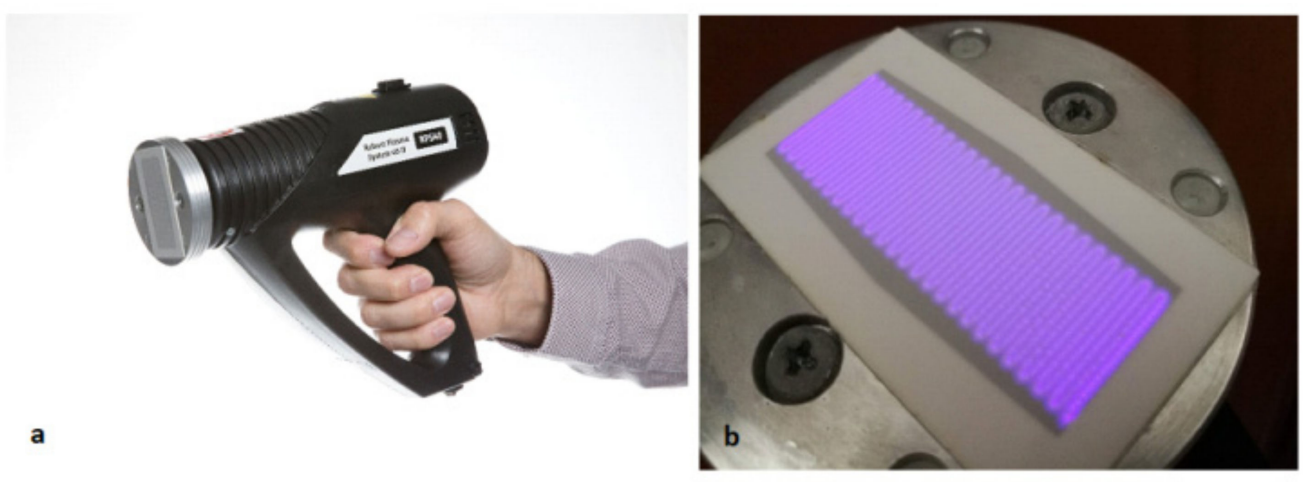

Figure 1. The photos are illustrating RPS40 plasma system, the general view of the handheld device (a) and the view of the macroscopically homogeneous DCSBD plasma layer generated in ambient air (b).

This type of plasma system is a minimized version of the classical DCSBD plasma source [51] which has been successfully investigated and used for surface treatment of a wide range of materials [52-56] including the treatment of the plant seeds [19,57-59] and application for bio-decontamination [60-62] in recent years. The electrodes system of RPS40 consists of an alumina plate with 25 pairs of parallel conductive strips with the width $0.5 \mathrm{~mm}$ and separated from each other by $0.5 \mathrm{~mm}$ gap and is supplied by a sinusoidal high voltage with a frequency $\sim 28 \mathrm{kHz}$ and power input of $40 \mathrm{~W}$. To prevent the undesirable sparking between the adjacent electrodes, these are isolated from each other by a thin $(0.15 \mathrm{~mm})$ dielectric layer. As shown in Figure 1b, RPS40 generates on the surface of the alumina plate with the dielectric layer a diffuse, macroscopically homogeneous plasma layer with the dimensions of $50 \mathrm{~mm} \times 20 \mathrm{~mm}$, whereas the effective thickness in ambient air is $0.2-0.3 \mathrm{~mm}$. During the operation, the electrode system is cooled down by passive heat dissipation through an aluminium housing, which is simultaneously cooled by a fan. Because of the effective cooling of the electrode system, the temperature of the alumina plate was less than $60^{\circ} \mathrm{C}$ for the maximum operation time. The implementation of the RPS40 or standard DCSBD plasma source into the clinical environment is undemanding. It does not require compliance with any particular operating conditions. No special gases are required, as the treatment can be carried out in ambient air. DCSBD plasma systems should be mounted in the holder for adjustment the optimised distance during the treatment and placed in a fume hood to exhaust ozone and nitrogen oxides. For powering RPS40 and a standard DCSBD plasma source, an electrical network with a $230 \mathrm{~V}(\mathrm{AC})$ voltage is needed.

\subsection{Sample Collection and Treatment}

Semen samples for this study were obtained from sixty healthy donors (age of $24.6 \pm 2.1$ years). The inclusion criteria for the donors were: (1) normal semen quality parameters accommodating the World Health Organization (WHO) guidelines (volume $\geq 1.5 \mathrm{~mL}$, concentration $\geq 15$ million $/ \mathrm{mL}$, motility $\geq 40 \%$ and morphology $\geq 4 \%$ ); (2) no sexually transmitted infections; and (3) may or may not have initiated a pregnancy in the past [63]. In order to trespass possible difficulties associated with potential limitations 
of the chemiluminescent ROS quantification, only ejaculates free from leukocytes were accepted for subsequent experiments. All donors provided informed consent to use their specimens for the purposes of this study. All procedures performed in the study involving human participants were in accordance with the ethical standards of the institutional and/or national research committee and with the 1964 Helsinki Declaration and its later amendments or comparable ethical standards. This article does not contain any experiments with animals performed by any of the authors. The samples were collected following 2-3 days of abstinence and allowed to liquefy for $30 \mathrm{~min}$ at $37^{\circ} \mathrm{C}$ before further processing. Nine samples were excluded for not accomplishing the WHO criteria.

Following liquefaction, the samples were diluted in physiological saline solution (B. Braun Melsungen AG, Melsungen, Germany) to a final concentration of 10 million $/ \mathrm{mL}$, placed into 6-well plates and subjected to NTP treatment using the RPS40 device. The distance of the thin plasma layer from the samples was set to $2 \mathrm{~cm}$, with exposure times of $0 \mathrm{~s}$ (control), $15 \mathrm{~s}, 30 \mathrm{~s}, 60 \mathrm{~s}$ and $90 \mathrm{~s}$. Selected experimental assessments of the sperm quality were performed immediately following the NTP treatment $(0 \mathrm{~h})$ and after a $2 \mathrm{~h}$ culture at $37^{\circ} \mathrm{C}$.

\subsection{CASA (Computer-Assisted Sperm Analysis)}

The CASA analysis was performed with the HTM TOX IVOS II. system (version 14.0; Hamilton-Thorne Biosciences, Beverly, MA, USA). Ten $\mu$ L of each sample were transferred to the Makler counting chamber (10 $\mu \mathrm{m}$ depth; Sefi Medical Instruments, Haifa, Israel), which was subsequently placed into the heated $\left(37^{\circ} \mathrm{C}\right)$ microscopic chamber of the CASA instrument. The output data were obtained using the Animal motility program (HamiltonThorne Biosciences, Beverly, MA, USA) [64]. In the case of this study, we were particularly interested in the overall motility (MOT; percentage of spermatozoa with a motility $\geq$ $5 \mu \mathrm{m} / \mathrm{s}$; \%) and progressive motility (PROG; percentage of spermatozoa with a motility $\geq 40 \mu \mathrm{m} / \mathrm{s} ; \%)$. Secondary motility characteristics, including path velocity (VAP; $\mu \mathrm{m} / \mathrm{s}$ ), straight line velocity (VSL; $\mu \mathrm{m} / \mathrm{s}$ ), curvilinear velocity (VCL; $\mu \mathrm{m} / \mathrm{s}$ ), lateral amplitude $(\mathrm{ALH} ; \mu \mathrm{m})$, beat frequency $(\mathrm{BCF} ; \mathrm{Hz})$, straightness $(\mathrm{STR} ; \%)$ and linearity $(\mathrm{LIN} ; \%)$ were evaluated as well.

\subsection{Membrane Integrity}

The commercially available Annexin-V-FLUOS kit (Roche Applied Science, Basel, Switzerland) was used to evaluate the membrane stability of the control and experimental samples. Using a dual staining with Annexin-V (AV) and propidium iodide (PI), it is possible to distinguish 3 categories of cells: cells in the early stage of apoptosis, which are in principle still alive, however, with an initial loss of selective membrane permeability (AV-positive/PI-negative), dead cells in necrosis or late-stage apoptosis with a perforated membrane (AV-positive/PI-positive) and, finally, living cells with an intact membrane that do not exhibit a signal for AV or PI [65].

For this assay, $10^{6}$ spermatozoa were transferred into Eppendorf tubes. Subsequently, $50 \mu \mathrm{L}$ incubation buffer, $1 \mu \mathrm{L} \mathrm{AV}$ and $1 \mu \mathrm{L}$ PI were added to each sample. The tubes were covered with foil and incubated for $30 \mathrm{~min}$ at $37^{\circ} \mathrm{C}$. Following incubation, the samples were stained with $10 \mu \mathrm{L}$ DAPI (4',6-diamidino-2-phenylindole; Sigma-Aldrich, St. Louis, MO, USA; $1 \mu \mathrm{M}$ in PBS), pipetted into a black opaque 96-well plate and the fluorescence intensity for each stain was quantified using a combined spectro-fluoro-luminometer (Glomax Multi ${ }^{+}$; Promega Corporation, Madison, WI, USA). The data are expressed as $\%$ apoptotic cells and $\%$ necrotic cells, respectively.

\subsection{Mitochondrial Activity}

The MTT test is a colorimetric method designed to determine the viability of eukaryotic cells by measuring their mitochondrial metabolic activity. The principle of the technique is based on the reduction of the yellow MTT tetrazolium salt to blue-violet, water-insoluble formazan crystals by the enzymatic activity of mitochondrial dehydrogenases, primarily by 
the succinate dehydrogenase complex of the respiratory chain of functional mitochondria within an active cell [66].

First, $200 \mu \mathrm{L}$ of the control and experimental samples were transferred from the culture plates into a 96-well plate. Subsequently, $20 \mu \mathrm{L}$ of the MTT tetrazolium (Sigma-Aldrich, St. Louis, MO, USA) previously dissolved in Dulbecco's PBS (phosphate-buffered saline without $\mathrm{Ca}^{2+}$ or $\mathrm{Mg}^{2+}$; Sigma-Aldrich, St. Louis, MO, USA) were added to each specimen and the samples were incubated at $37^{\circ} \mathrm{C}$ for one hour. The reaction was stopped with $80 \mu \mathrm{L}$ of acidic isopropanol (Centralchem, Bratislava, Slovakia). The amount of formazan was determined spectrophotometrically (Multiskan FC microplate photometer; Thermo Fisher Scientific Inc., Waltham, MA, USA). The absorbance was measured at $570 \mathrm{~nm}$ (maximum for formazan) versus $620 \mathrm{~nm}$ (reference values). The values collected from the experimental groups are expressed in percentage of the control, which was set to $100 \%$ [41].

\subsection{Mitochondrial Membrane Potential}

In order to have a closer look on the sperm mitochondrial behaviour following exposure to NTP, the mitochondrial membrane potential $(\Delta \Psi \mathrm{m})$ was examined with the Mitochondrial Membrane Potential Assay Kit (Cayman Chemical, Ann Arbor, MI, USA). The protocol takes advantage of the fluorescent JC- 1 cationic dye, which binds to the mitochondria and adjusts its fluorescent features depending on its aggregation. In the case of cells with healthy mitochondria with a high $\Delta \Psi \mathrm{m}, \mathrm{JC}-1$ complexes emerge with red fluorescence. In the cells with disrupted mitochondria exhibiting a low $\Delta \Psi \mathrm{m}$, the JC-1 dye remains in its monomeric form with green fluorescence.

One million cells were transferred into Eppendorf tubes, the volume of the cell suspension was adjusted to $100 \mu \mathrm{L}$ with PBS and subsequently stained with $5 \mu \mathrm{L}$ JC-1 working solution. Following incubation $\left(20 \mathrm{~min}, 37^{\circ} \mathrm{C}\right.$, dark conditions) the stained suspensions were washed twice with PBS, transferred to a black opaque 96-well plate and the fluorescence intensity for the JC-1 monomers and polymers was quantified using a combined spectro-fluoro-luminometer (Glomax Multi ${ }^{+}$; Promega Corporation, Madison, WI, USA). The resulting $\Delta \Psi \mathrm{m}$ is expressed as the ratio of JC-1 complexes to JC-1 monomers (red/green ratio) [67].

\subsection{Global ROS Production}

The chemiluminescent method to determine the amount of ROS in this study is based on a direct quantification of intracellular as well as extracellular ROS due to a nonspecific reaction of the probe (luminol) with oxidizing agents (ROS) within the cell or its surroundings [68].

One hundred $\mu \mathrm{L}$ of the control or experimental cell suspension were transferred to a 96-well plate and subsequently treated with $2.5 \mu \mathrm{L}$ of $5 \mathrm{mM}$ freshly prepared luminol (Sigma-Aldrich, St. Louis, MO, USA). One hundred $\mu$ L PBS served as the experimental blank, while the negative control consisted of $100 \mu \mathrm{L}$ PBS and $2.5 \mu \mathrm{L}$ luminol. The positive control consisted of $100 \mu \mathrm{L}$ PBS, $12.5 \mu \mathrm{L} \mathrm{H}_{2} \mathrm{O}_{2}$ (33\%; Sigma-Aldrich, St. Louis, MO, USA) and $2.5 \mu \mathrm{L}$ luminol. The luminescence was measured with a combined spectro-fluoroluminometer (Glomax Multi ${ }^{+}$; Promega Corporation, Madison, WI, USA). The intensity of the light in the wells was evaluated by counting photons within 151-min cycles. The experimental results are expressed in relative light units per second per million sperm (RLU/s/106 sperm) [67].

\subsection{Superoxide Production}

The NBT test is a colorimetric protocol devised to estimate the extent of the superoxide production within the cell. The experimental approach of the technique is based on the intracellular reaction between nitroblue tetrazolium chloride and superoxide, leading to the formation of blue formazan crystals [69].

First, $200 \mu \mathrm{L}$ of the control and experimental samples were pipetted into a transparent 96-well plate. Subsequently, $100 \mu \mathrm{L}$ of the NBT tetrazolium (Sigma-Aldrich, St. Louis, 
MO, USA) previously dissolved in Dulbecco's PBS containing 1.5\% DMSO (Sigma-Aldrich, St. Louis, MO, USA) were added to each cell suspension. The samples were incubated at $37^{\circ} \mathrm{C}$ for one hour, subsequently centrifuged $(300 \times \mathrm{g}$ for $10 \mathrm{~min})$ and washed twice with PBS. The reaction was stopped with $2 \mathrm{M}$ potassium hydroxide $(\mathrm{KOH}$; Centralchem, Bratislava, Slovakia) dissolved in DMSO. The amount of formazan was quantified with the Multiskan FC microplate photometer (Thermo Fisher Scientific Inc., Waltham, MA, USA). The absorbance was measured at $570 \mathrm{~nm}$ versus $620 \mathrm{~nm}$ and the data obtained from the experimental groups are expressed in percentage of the control, which was set to $100 \%$ [40].

\subsection{DNA Fragmentation}

Sperm DNA fragmentation was assessed with the Halosperm ${ }^{\circledR}$ commercial kit (Halotech DNA, Madrid, Spain). Twenty $\mu \mathrm{L}$ of each control and experimental semen sample were mixed with low-melting point agarose provided by the kit. The semenagarose mix was transferred onto a microscopic slide pre-coated with agarose, covered with a coverslip and cooled down to $4{ }^{\circ} \mathrm{C}$ to solidify the agarose. The coverslips were then gently removed and the slides immersed into an acid solution for $7 \mathrm{~min}$. Subsequently, the slides were subjected to a lysis solution for $20 \mathrm{~min}$ and washed with distilled water for $5 \mathrm{~min}$. Finally, the slides were dehydrated in $70 \%$ and $100 \%$ ethanol for 2 min each and air-dried.

For the evaluation, the slides were stained with Sybr-Green $(2 \mu \mathrm{g} / \mathrm{mL}$ ) (Sigma Aldrich, St. Louis, MO, USA)/Vectashield (Vector Laboratories, USA) and at least 300 spermatozoa per sample were scored by one experienced observer with an epifluorescence microscope $(\times 40$, Leica Microsystems, Wetzlar, Germany) [70]. The proportion of spermatozoa with a damaged DNA molecule is expressed as a percentage.

\subsection{TBARS Assay}

An aliquot of each sample was centrifuged $(800 \times g, 10 \mathrm{~min})$ and the sperm pellet was sonicated $(28 \mathrm{kHz}, 30 \mathrm{~s})$ in the presence of the RIPA buffer (Sigma-Aldrich, St. Louis, $\mathrm{MO}$, USA) and protease inhibitor (Sigma-Aldrich, St. Louis, MO, USA). Following the second round of centrifugation $\left(11,828 \times g, 4{ }^{\circ} \mathrm{C}, 10 \mathrm{~min}\right)$ and purification, the lysates were subjected to the quantification of malondialdehyde (MDA), considered to be the principal marker of lipid peroxidation (LPO).

The sperm lysates were pre-treated with $5 \%$ sodium dodecyl sulphate (Sigma-Aldrich, St. Louis, MO, USA) and subsequently exposed to $0.53 \%$ thiobarbituric acid (TBA; Sigma-Aldrich, St. Louis, MO, USA) dissolved in $20 \%$ acetic acid ( $\mathrm{pH} 3.5$; Centralchem, Bratislava, Slovakia) under high-temperature conditions $\left(90-100^{\circ} \mathrm{C}\right)$ for $1 \mathrm{~h}$. Afterwards, the samples were cooled down for $10 \mathrm{~min}$ and centrifuged $(1750 \times g, 10 \mathrm{~min})$. The supernatants $(150 \mu \mathrm{L})$ were transferred into a transparent 96-well plate and the levels of MDA were assessed at $540 \mathrm{~nm}$ using the Glomax microplate spectrophotometer (Promega, Madison, WI, USA). MDA levels are expressed as $\mu \mathrm{mol} / \mathrm{L}$ [71].

\subsection{Statistical Analysis}

All data were processed with the GraphPad Prism statistical program (version 9.0.0. for Mac; GraphPad Software, San Diego, CA, USA). First, all data were subjected to the ShapiroWilk normality test considering a normal (Gaussian) distribution. All data sets passed the normality test with non-significant results at the alpha level of 0.05 . Descriptive statistical characteristics (mean, standard error of the mean), One-way ANOVA and Dunnett's posttest were chosen for subsequent analyses. The experimental groups were compared with the control. The level of significance was set at ${ }^{* * * *} p<0.0001 ;{ }^{* * *} p<0.001 ;{ }^{* *} p<0.01$; ${ }^{*} p<0.05$. 
Author Contributions: Conceptualization, E.T., E.G., S.K. and D.L.; methodology, E.T. and D.K.; validation, E.T. and D.L.; formal analysis, E.T.; investigation, E.T.; resources, E.T. and D.K.; writingoriginal draft preparation, E.T. and D.L.; writing—review and editing, S.K., D.L., E.G. and D.K.; supervision, E.G.; project administration, E.G. and E.T.; funding acquisition, E.G. All authors have read and agreed to the published version of the manuscript.

Funding: This research was funded by the Slovak Research and Development Agency grants APVV16-0216, APVV-15-0544 and by the project VEGA 1/0460/21.

Institutional Review Board Statement: The experimental design was approved by the Ethic Committee at the St. Svorad Hospital Zobor-Nitra, n. o., protocol number 030809/2015. All procedures performed in the study involving human participants were in accordance with the ethical standards of the institutional and/or national research committee and with the 1964 Helsinki Declaration and its later amendments or comparable ethical standards.

Informed Consent Statement: Informed consent was obtained from all subjects involved in the study.

Data Availability Statement: The data presented in this study are available on request from the corresponding author.

Acknowledgments: We would like to thank Anna Zahoranová for her supervision and assistance during manuscript preparation.

Conflicts of Interest: The authors declare no conflict of interest. The funders had no role in the design of the study; in the collection, analyses, or interpretation of data; in the writing of the manuscript, or in the decision to publish the results.

\section{References}

1. Dissanayake, D.M.I.H.; Keerthirathna, W.L.R.; Peiris, L.D.C. Male infertility problem: A contemporary review on present status and future perspective. Gend. Genome 2019, 3, 1-7. [CrossRef]

2. Ruvolo, G.; Fattouh, R.R.; Bosco, L.; Brucculeri, A.M.; Cittadini, E. New molecular markers for the evaluation of gamete quality. J. Assist. Reprod. Genet. 2013, 30, 207-212. [CrossRef] [PubMed]

3. Moretti, E.; Capitani, S.; Figura, N.; Pammolli, A.; Federico, M.G.; Giannerini, V.; Collodel, G. The presence of bacteria species in semen and sperm quality. J. Assist. Reprod. Genet. 2009, 26, 47-56. [CrossRef] [PubMed]

4. Prabha, V.; Thakur, N.; Kaur, S.; Kaur, N.; Sihngh, A.; Kala, S. Agglutination of human spermatozoa due to human semen culture bacterial isolates bearing sperm ligand. Am. J. Biomed. Sci. 2009, 1, 126-132. [CrossRef]

5. Vilvanathan, S.; Kandasamy, B.; Jayachandran, A.L.; Sathiyanarayanan, S.; Singaravelu, V.T.; Krishnamurthy, V.; Elangovan, V. Bacteriospermia and its impact on basic semen parameters among infertile men. Interdiscip. Perspect. Infect. Dis. 2016, 2016, 2614692. [CrossRef]

6. Domes, T.; Lo, K.C.; Grober, E.D.; Mullen, J.B.M.; Mazzulli, T.; Jarvi, K. The incidence and effect of bacteriospermia and elevated seminal leukocytes on semen parameters. Fertil. Steril. 2012, 97, 1050-1055. [CrossRef]

7. Seidman, D.S.; Madjar, I.; Levron, J.; Levran, D.; Mashiach, S.; Dor, J. Testicular sperm aspiration and intracytoplasmic sperm injection for persistent infection of the ejaculate. Fertil. Steril. 1999, 71, 564-566. [CrossRef]

8. $\quad$ Liversedge, N.H.; Jenkins, J.M.; Keay, S.D.; McLaughin, E.A.; Al-Sufyan, H.; Maile, L.A.; Joels, L.A.; Hull, M.G.R. Antibiotic treatment based on seminal cultures from asymptomatic male partners in in-vitro fertilization is unnecessary and may be detrimental. Hum. Reprod. 1996, 11, 1227-1231. [CrossRef]

9. Khaki, A. Assessment on the adverse effects of aminoglycosides and flouroquinolone on sperm parameters and male reproductive tissue: A systematic review. Iran. J. Reprod. Med. 2015, 13, 125-134.

10. Fahmy, M.A.; Farghaly, A.A.; Omara, E.A.; Hassan, Z.M.; Aly, F.A.E.; Donya, S.M.; Ibrahim, A.A.E.; Bayoumy, E.M. Amoxicillinclavulanic acid induced sperm abnormalities and histopathological changes in mice. Asian Pac. J. Trop. Biomed. 2017, 7, 809-816. [CrossRef]

11. Guo, J.; Huang, K.; Wang, J. Bactericidal effect of various non-thermal plasma agents and the influence of experimental conditions in microbial inactivation: A review. Food Control 2015, 50, 482-490. [CrossRef]

12. Kalghatgi, S.; Kelly, C.M.; Cerchar, E.; Torabi, B.; Alekseev, O.; Fridman, A.; Friedman, G.; Azizkhan-Clifford, J. Effects of non-thermal plasma on mammalian cells. PLoS ONE 2011, 6, e16270. [CrossRef]

13. Beate, H.T.W.; Klaus-Dieter, W.; Ulrike, L. Non-thermal atmospheric-pressure plasma possible application in wound healing. Biomol. Ther. 2014, 22, 477-490.

14. Kim, C.H.; Bahn, J.H.; Lee, S.H.; Kim, G.Y.; Jun, S.I.; Lee, K.; Baek, S.J. Induction of cell growth arrest by atmospheric non-thermal plasma in colorectal cancer cells. J. Biotechnol. 2010, 150, 530-538. [CrossRef]

15. Hanon, M.S.; Mazhir, S.N.; Hussein, E.A. Effect of dielectric barrier discharge on sperm motility and influence on oxidative stress in patient with asthenospermia. AIP Conf. Proc. 2019, 2190, 020091. 
16. Mazhir, S.N.; Al-Ahmed, H.I.; Hanon, M.S.; Ali, A.H. Influence of cold plasma on sperm motility and oxidative stress in patient with asthenospermia. Biosci. Res. 2019, 16, 480-484.

17. Zhang, J.J.; Do, H.L.; Chandimali, N.; Lee, S.B.; Mok, Y.S.; Kim, N.; Kim, S.B.; Kwon, T.; Jeong, D.K. Non-thermal plasma treatment improves chicken sperm motility via the regulation of demethylation levels. Sci. Rep. 2018, 8, 7576. [CrossRef]

18. Zhang, J.J.; Huynh, D.L.; Chandimali, N.; Kang, T.Y.; Kim, N.; Mok, Y.S.; Kwon, T.; Jeong, D.K. Growth and male reproduction improvement of non-thermal dielectric barrier discharge plasma treatment on chickens. J. Phys. D Appl. Phys. 2018, $51,205201$. [CrossRef]

19. Zahoranová, A.; Hoppanová, L.; Šimončicová, J.; Tučeková, Z.; Medvecká, V.; Hudecová, D.; Kaliňáková, B.; Kováčik, D.; Černák, M. Effect of cold atmospheric pressure plasma on maize seeds: Enhancement of seedlings growth and surface microorganisms inactivation. Plasma Chem. Plasma Process. 2018, 38, 969-988. [CrossRef]

20. Dutta, S.; Majzoub, A.; Agarwal, A. Oxidative stress and sperm function: A systematic review on evaluation and management. Arab. J. Urol. 2019, 17, 87-97. [CrossRef]

21. Graves, D.B. Low temperature plasma biomedicine: A tutorial review. Phys. Plasmas 2014, 21, 080901. [CrossRef]

22. Boehm, D.; Heslin, C.; Cullen, P.; Bourke, P. Cytotoxic and mutagenic potential of solutions exposed to cold atmospheric plasma. Sci. Rep. 2016, 6, 21464. [CrossRef] [PubMed]

23. Khosravifarsani, M.; Shabestani-Monfared, A.; Pouramir, M.; Zabihi, E. Hydroxyl radical $\left({ }^{\circ} \mathrm{OH}\right)$ scavenger power of tris (hydroxymethyl) compared to phosphate buffer. J. Mol. Biol. Res. 2016, 6, 52. [CrossRef]

24. Gosálvez, J.; Tvrdá, E.; Agarwal, A. Free radical and superoxide reactivity detection in semen quality assessment: Past, present, and future. J. Assist. Reprod. Genet. 2017, 34, 697-707. [CrossRef]

25. Lunov, O.; Zablotskii, V.; Churpita, O.; Chánová, E.; Syková, E.; Dejneka, A.; Kubinová, S. Cell death induced by ozone and various non-thermal plasmas: Therapeutic perspectives and limitations. Sci. Rep. 2014, 20, 7129. [CrossRef]

26. Cain, W.S.; Schmidt, R.; Wolkoff, P. Olfactory detection of ozone and D-limonene: Reactants in indoor spaces. Indoor Air 2007, 17, 337-347. [CrossRef]

27. Gradil, C.; Eaglesome, M.D.; Stewart, B.; Garcia, M.M.; Quimby, F. Bactericidal effects of ozone at nonspermicidal concentrations. Can. J. Vet. Res. 1995, 59, 183-186.

28. Lackmann, J.W.; Schneider, S.; Edengeiser, E.; Jarzina, F.; Brinckmann, S.; Steinborn, E.; Havenith, M.; Benedikt, J.; Bandow, J.E. Photons and particles emitted from cold atmospheric-pressure plasma inactivate bacteria and biomolecules independently and synergistically. J. R. Soc. Interface 2013, 10, 20130591. [CrossRef]

29. Yan, D.; Sherman, J.H.; Keidar, M. Cold atmospheric plasma, a novel promising anti-cancer treatment modality. Oncotarget 2017, 8, 15977-15995. [CrossRef]

30. Torres, E.R.; Abad, C.; Piñero, S.; Proverbio, T.; Marín, R.; Proverbio, F.; Camejo, M.I. Effect of ultraviolet C irradiation on human sperm motility and lipid peroxidation. Int. J. Radiat. Biol. 2010, 86, 187-193. [CrossRef]

31. Sharma, R.; Rajput, N.; Bansal, K.; Highland, H. Effect of low level, short wavelength ultraviolet radiation on sperm chromatin. Asian Pac. J. Reprod. 2017, 6, 252. [CrossRef]

32. König, K.; Tadir, Y.; Patrizio, P.; Berns, M.W.; Tromberg, B.J. Andrology: Effects of ultraviolet exposure and near infrared laser tweezers on human spermatozoa. Hum. Reprod. 1996, 11, 2162-2164. [CrossRef]

33. Graves, D.B. The emerging role of reactive oxygen and nitrogen species in redox biology and some implications for plasma applications to medicine and biology. J. Phys. D Appl. Phys. 2012, 45, 263001. [CrossRef]

34. Du Plessis, S.S.; McAllister, D.A.; Luu, A.; Savia, J.; Agarwal, A.; Lampiao, F. Effects of $\mathrm{H}_{2} \mathrm{O}_{2}$ exposure on human sperm motility parameters, reactive oxygen species levels and nitric oxide levels. Andrologia 2010, 42, 206-210. [CrossRef]

35. Linschooten, J.O.; Laubenthal, J.; Cemeli, E.; Baumgartner, A.; Anderson, D.; Sipinen, V.E.; Brunborg, G.; Haenen, G.R.; Fthenou, E.; Briedé, J.J.; et al. Incomplete protection of genetic integrity of mature spermatozoa against oxidative stress. Reprod. Toxicol. 2011, 32, 106-111. [CrossRef]

36. Adami, L.N.G.; Belardin, L.B.; Lima, B.T.; Jeremias, J.T.; Antoniassi, M.P.; Okada, F.K.; Bertolla, R.P. Effect of in vitro vitamin E (alpha-tocopherol) supplementation in human spermatozoon submitted to oxidative stress. Andrologia 2018. [CrossRef]

37. Aitken, R.J.; Whiting, S.; de Iuliis, G.N.; McClymont, S.; Mitchell, L.A.; Baker, M.A. Electrophilic aldehydes generated by sperm metabolism activate mitochondrial reactive oxygen species generation and apoptosis by targeting succinate dehydrogenase. J. Biol. Chem. 2012, 287, 33048-33060. [CrossRef]

38. Moscatelli, N.; Spagnolo, B.; Pisanello, M.; Lemma, E.D.; de Vittorio, M.; Zara, V.; Pisanello, F.; Ferramosca, A. Single-cell-based evaluation of sperm progressive motility via fluorescent assessment of mitochondria membrane potential. Sci. Rep. 2017, 7, 17931. [CrossRef]

39. Lukacova, J.; Jambor, T.; Knazicka, Z.; Tvrda, E.; Kolesarova, A.; Lukac, N. Dose- and time-dependent effects of bisphenol A on bovine spermatozoa in vitro. J. Environ. Sci. Health A 2015, 50, 669-676. [CrossRef]

40. Lukac, N.; Lukacova, J.; Pinto, B.; Knazicka, Z.; Tvrda, E.; Massanyi, P. The effect of nonylphenol on the motility and viability of bovine spermatozoa in vitro. J. Environ. Sci. Health A 2013, 48, 973-979. [CrossRef]

41. Tvrdá, E.; Lukáč, N.; Lukáčová, J.; Jambor, T.; Massányi, P. Dose- and time-dependent in vitro effects of divalent and trivalent iron on the activity of bovine spermatozoa. Biol. Trace Elem. Res. 2015, 167, 36-47. [CrossRef]

42. Guthrie, H.D.; Welch, G.R.; Long, J.A. Mitochondrial function and reactive oxygen species action in relation to boar motility. Theriogenology 2008, 70, 1209-1215. [CrossRef] 
43. Baumber, J.; Ball, B.A.; Gravance, C.G.; Medina, V.; Davies-Morel, M.C. The effect of reactive oxygen species on equine sperm motility, viability, acrosomal integrity, mitochondrial membrane potential, and membrane lipid peroxidation. J. Androl. 2000, 21, 895-902.

44. Condorelli, R.A.; La Vignera, S.; Giacone, F.; Iacoviello, L.; Vicari, E.; Mongioi, L.; Calogero, A.E. In vitro effects of nicotine on sperm motility and bio-functional flow cytometry sperm parameters. Int. J. Immunopathol. Pharmacol. 2013, 26, 739-746. [CrossRef]

45. Wang, E.; Huang, Y.; Du, Q.; Sun, Y. Silver nanoparticle induced toxicity to human sperm by increasing ROS (reactive oxygen species) production and DNA damage. Environ. Toxicol. Pharmacol. 2017, 52, 193-199. [CrossRef]

46. Aitken, R.J.; Baker, M.A.; Nixon, B. Are sperm capacitation and apoptosis the opposite ends of a continuum driven by oxidative stress? Asian J. Androl. 2015, 17, 633-639. [CrossRef]

47. Hosen, M.B.; Islam, M.R.; Begum, F.; Kabir, Y.; Howlader, M.Z. Oxidative stress induced sperm DNA damage, a possible reason for male infertility. Iran. J. Reprod. Med. 2015, 13, 525-532.

48. Wright, C.; Milne, S.; Leeson, H. Sperm DNA damage caused by oxidative stress: Modifiable clinical, lifestyle and nutritional factors in male infertility. Reprod. Biomed. Online 2014, 28, 684-703. [CrossRef]

49. Adamovich, I.; Baalrud, S.D.; Bogaerts, A.; Bruggeman, P.J.; Cappelli, M.; Colombo, V.; Czarnetzki, U.; Ebert, U.; Eden, J.G.; Favia, P.; et al. The 2017 plasma roadmap: Low temperature plasma science and technology. Phys. D Appl. Phys. 2017, $50,323001$. [CrossRef]

50. Scholtz, V.; Pazlarova, J.; Souskova, H.; Khun, J.; Julak, J. Nonthermal plasma-A tool for decontamination and disinfection. Biotechnol. Adv. 2015, 33, 1108-1119. [CrossRef]

51. Šimor, M.; Ráhel', J.; Vojtek, P.; Černák, M. Atmospheric-pressure diffuse coplanar surface discharge for surface treatments. Appl. Phys. Lett. 2002, 81, 2716-2718. [CrossRef]

52. Kováčik, D.; Černák, M.; Zahoranová, A.; Ráhel', J.; St’ahel, P. Low-cost, high-speed hydrophilic finishing of lightweight polypropylene nonwovens by ambient air plasma. In Horizons in World Physics; Reimer, A., Ed.; Nova Science Publishers: New York, NY, USA, 2017; pp. 85-103.

53. Hanusová, J.; Kováčik, D.; Stupavská, M.; Černák, M. Atmospheric pressure plasma treatment of polyamide-12 foils. Open Chem. 2015, 13, 382-388. [CrossRef]

54. Buček, A.; Brablec, A.; Kováčik, D.; St'ahel, P.; Černák, M. Glass bond adhesive strength improvement by DCSBD atmosphericpressure plasma treatment. Int. J. Adhes. Adhes. 2017, 78, 1-3. [CrossRef]

55. Bónová, L.; Zahoranová, A.; Kováčik, D.; Zahoran, M.; Mičušík, M.; Černák, M. Atmospheric pressure plasma treatment of flat aluminum surface. Appl. Surf. Sci. 2015, 331, 79-86. [CrossRef]

56. Medvecká, V.; Kováčik, D.; Zahoranová, A.; Černák, M. Atmospheric pressure plasma assisted calcination by the preparation of $\mathrm{TiO}_{2}$ fibers in submicron scale. Appl. Surf. Sci. 2018, 428, 609-615. [CrossRef]

57. Zahoranová, A.; Henselová, M.; Hudecová, D.; Kaliňáková, B.; Kováčik, D.; Medvecká, V.; Černák, M. Effect of cold atmospheric pressure plasma on the wheat seedlings vigor and on the inactivation of microorganisms on the seeds surface. Plasma Chem. Plasma Process. 2016, 36, 397-414. [CrossRef]

58. Kyzek, S.; Holubová, L’.; Medvecká, V.; Tomeková, J.; Gálová, E.; Zahoranová, A. Cold atmospheric pressure plasma can induce adaptive response in pea seeds. Plasma Chem. Plasma Process. 2019, 39, 475-486. [CrossRef]

59. Švubová, R.; Kyzek, S.; Medvecká, V.; Slováková, L'.; Gálová, E.; Zahoranová, A. Novel insight at the effect of cold atmospheric pressure plasma on the activity of enzymes essential for the germination of pea (Pisum sativum L. cv. Prophet) seeds. Plasma Chem. Plasma Process. 2020, 40, 1221-1240. [CrossRef]

60. Mošovská, S.; Medvecká, V.; Gregová, M.; Tomeková, J.; Valík, L'.; Mikulajová, A.; Zahoranová, A. Plasma inactivation of Aspergillus flavus on hazelnut surface in a diffuse barrier discharge using different working gases. Food Control 2019, 104, $256-261$. [CrossRef]

61. Šimončicová, J.; Kaliňáková, B.; Kováčik, D.; Medvecká, V.; Lakatoš, B.; Kryštofová, S.; Hoppanová, L.; Palušková, V.; Hudecová, D.; Durina, P.; et al. Cold plasma treatment triggers antioxidative defense system and induces changes in hyphal surface and subcellular structures of Aspergillus flavus. Appl. Microbiol. Biotechnol. 2018, 102, 6647-6658. [CrossRef]

62. Mošovská, S.; Medvecká, V.; Halászová, N.; Ďurina, P.; Valík, L'.; Mikulajová, A.; Zahoranová, A. Cold atmospheric pressure ambient air plasma inhibition of pathogenic bacteria on the surface of black pepper. Food Res. Int. 2018, 106, 862-869. [CrossRef] [PubMed]

63. Björndahl, L.; Barratt, C.L.R.; Mortimer, D.; Jouannet, P. 'How to count sperm properly': Checklist for acceptability of studies based on human semen analysis. Hum. Reprod. 2016, 31, 227-232. [CrossRef] [PubMed]

64. Mortimer, D.; Mortimer, S.T. Computer-aided sperm analysis (CASA) of sperm motility and hyperactivation. Methods Mol. Biol. 2013, 927, 77-87. [PubMed]

65. Shen, H.M.; Dai, J.; Chia, S.E.; Lim, A.; Ong, C.N. Detection of apoptotic alterations in sperm in subfertile patients and their correlations with sperm quality. Hum. Reprod. 2002, 17, 1266-1273. [CrossRef]

66. Mosmann, T. Rapid colorimetric assay for cellular growth and survival: Application to proliferation and cytotoxicity assays. J. Immunol. Methods 1983, 65, 55-63. [CrossRef]

67. Duracka, M.; Lukac, N.; Kacaniova, M.; Kantor, A.; Hleba, L.; Ondruska, L.; Tvrda, E. Antibiotics versus natural biomolecules: The case of in vitro induced bacteriospermia by Enterococcus faecalis in rabbit semen. Molecules 2019, 24, 4329. [CrossRef] 
68. Agarwal, A.; Qiu, E.; Sharma, R. Laboratory assessment of oxidative stress in semen. Arab J. Urol. 2017, 16, 77-86. [CrossRef]

69. Tvrda, E. NBT test. In Oxidants, Antioxidants and Impact of the Oxidative Status in Male Reproduction, 1st ed.; Henkel, R., Samanta, L., Agarwal, A., Eds.; Elsevier: Amsterdam, The Netherlands, 2018; pp. 195-205.

70. Tvrdá, E.; Arroyo, F.; Gosálvez, J. Dynamic assessment of human sperm DNA damage I: The effect of seminal plasma-sperm co-incubation after ejaculation. Int. Urol. Nephrol. 2018, 50, 1381-1388. [CrossRef]

71. Kovacik, A.; Tirpak, F.; Tomka, M.; Miskeje, M.; Tvrda, E.; Arvay, J.; Andreji, J.; Slanina, T.; Gabor, M.; Hleba, L.; et al. Trace elements content in semen and their interactions with sperm quality and RedOx status in freshwater fish Cyprinus carpio: A correlation study. J. Trace Elem. Med. Biol. 2018, 50, 399-407. [CrossRef] 